\title{
Development and validation of a stability-indicating LC-UV and LC-MS/MS methods for quantitative analysis of anisomycin and identification of degradation products
}

\author{
Ljiljana Tolićc ${ }^{*}$, Svetlana Grujić², Mila Laušević
}

${ }^{1}$ Innovation Center of the Faculty of Technology and Metallurgy, Karnegijeva 4, Belgrade, Serbia, ${ }^{2}$ Faculty of Technology and Metallurgy, University of Belgrade, Karnegijeva 4, Belgrade, Serbia

\begin{abstract}
Multifunctional drug anisomycin was subjected to forced degradation in accordance with International Conference on Harmonisation (ICH) guidelines for the first time. The drug was exposed to the recommended stress conditions of hydrolysis (acidic, alkaline and neutral), oxidation, thermal stress and photolysis, in order to investigate its stability. Optimized LC-MS/MS method was validated as recommended by ICH Q2(R1) guideline with respect to the specificity, accuracy, precision, limits of detection and quantitation, linearity and robustness. Anisomycin exhibited high instability under alkaline and thermal (neutral hydrolysis) conditions. It showed moderate stability under acidic, neutral, oxidative, thermal (acidic hydrolysis) and photolytic conditions, with the lowest degradation level observed in the case of light and oxidation stress. Formation of the same degradation product, identified as deacetylanisomycin, was observed under all applied stress conditions.
\end{abstract}

Keywords: Anisomycin/forced degradation. Stability-indicating. LC-MS/MS/validation. Deacetylanisomycin.

\section{INTRODUCTION}

Anisomycin, also known as flagecidin, is a pyrrolidine antibiotic isolated from two species of Streptomyces, identified as S. griseolus and $S$. roseochromogenes (Sobin, Tanner, 1954). Anisomycin has an empirical formula of $\mathrm{C}_{14} \mathrm{H}_{19} \mathrm{NO}_{4}$ and its IUPAC name is 2-p-methoxyphenylmethyl-3-acetoxy-4hydroxypyrrolidine. In the previous studies it was shown that anisomycin exhibits multifunctional properties, however, it is still not clinically used. Anisomycin is a well-known inhibitor of protein synthesis (Grollman, 1967; Barbacid, Vazquez, 1974). Its effects on memory and influence on behavior have been widely reported (Cohen et al., 2006; Pena et al., 2014; Lopez et al., 2015). Therefore, anisomycin is proposed as a potential psychiatric drug. Namely, in some studies on animals it was shown that it affects protein synthesis in amygdala, a part of brain that influences memory. As a result, anisomycin inhibits

\footnotetext{
*Correspondence: $\mathrm{Lj}$. Tolić. Innovation Center of the Faculty of Technology and Metallurgy, Karnegijeva 4, 11000 Belgrade, Serbia. E-mail: ljtolic@tmf.bg.ac.rs
}

the consolidation of new memories and can even cause amnesia (Nader, Schafe, Le Doux, 2000; Hardt, Wang, Nader, 2009; Ryan et al., 2015). Furthermore, previous findings have indicated that anisomycin may function as an immunosuppressant in low doses, and it has possible application in the treatment of some autoimmune diseases and the inhibition of the transplantation rejection (Xing et al., 2008; Sun et al., 2013). In the future, this drug might possibly be used in therapies as an antitumor agent since it was shown that anisomycin suppresses malignant tumor cell growth (Curtin, Cotter, 2002; Jin et al., 2013). Also, anisomycin possesses herbicidal activity, as well as the selective activity against pathogenic protozoa and fungi (Reddy, Kumar, Rao, 2005; Zhang et al., 2013). Still, some of the mechanisms of its action and additional areas of potential usage remain unknown (Macías-Silva, VázquezVictorio, Hernández-Damián, 2010).

It is of great importance to understand the stability of a drug molecule, i.e. to know how the quality of a drug varies with time under the influence of a variety of environmental factors. The International Conference on Harmonisation (ICH) guidelines on stability testing of new drug substances and products Q1A(R2) and Q1B (ICH, 2003; ICH, 1996) 
suggest stress studies on a drug to establish its stability characteristics. To the best of our knowledge, there are no such studies on anisomycin. Liquid chromatography (LC) is an analytical technique widely used in the pharmaceutical industry for investigation of drug degradation and analysis of the degradation products. Anisomycin has been identified and analyzed using liquid chromatography, as well as ultraviolet (UV), infrared and nuclear magnetic resonance spectroscopy, and mass spectrometry (Kirchmeier, Upton, 1978; LeFevre, Maier, Deng, 1993; Rusanova et al., 2000; Abdel-Aal et al., 2011; Tolić et al., 2015; Tolić et al., 2016). In our previous papers, liquid chromatography coupled to tandem mass spectrometry (LC-MS/MS) was used as a comparative method for investigation of anisomycin electrochemical degradation in standard solution and in urine (Tolić et al., 2015), as well as for determination of anisomycin in various tissues and serum (Tolić et al., 2016). In the later, the method was validated according to FDA guidelines for bioanalytical method validation (FDA, 2001). However, to the best of our knowledge, there are no stability-indicating LC-UV nor LC-MS/MS based methods validated according to ICH Q2(R1) guideline (ICH, 1994) used for investigation of anisomycin. Therefore, the aim of this work was to investigate degradation behavior of anisomycin in order to understand the stability of the drug molecule and to identify the degradation products. This was accomplished by exposing the drug to $\mathrm{ICH}$ recommended stress conditions of hydrolysis, oxidation, thermal stress and photolysis, and by analyzing the samples using optimized and validated stability-indicating LC-MS/MS method.

\section{MATERIAL AND METHODS}

\section{Chemicals and reagents}

The anisomycin standard (purity $\geq 98 \%$ ) was obtained from Fermentek (Jerusalem, Israel). HPLC grade methanol, acetonitrile and acetic acid were supplied by Sigma-Aldrich (St. Louis, MO, USA). All analytical grade reagents (35\% hydrochloric acid, sodium hydroxide and 30\% hydrogen peroxide) were purchased from LachNer (Neratovica, Czech Republic). Deionized water was obtained by passing the distilled water through a GenPure ultrapure water system (TKA, Niederelbert, Germany).

\section{Preparation of standard solutions}

The stock standard solution was prepared at the concentration of $100 \mu \mathrm{g} \mathrm{mL}^{-1}$ by dissolving $1.0 \mathrm{mg}$ of anisomycin in $10 \mathrm{~mL}$ of methanol. The working standard solutions were prepared by diluting the stock standard solution with methanol to the appropriate concentrations. In the case of acidic hydrolysis, acetonitrile was used instead of methanol. Namely, alcohols should not be used as solvents under acidic conditions due to their reactivity (Alsante et al., 2007).

\section{Liquid chromatography}

Previously developed LC-MS/MS method for identification and quantification of anisomycin (Tolić et al., 2015; Tolić et al., 2016) was slightly changed and adjusted in order to achieve chromatographic separation of anisomycin and its degradation product. Liquid chromatography was performed using a Dionex UltiMate $3000^{\circledR}$ LC system (Thermo Fisher Scientific, Waltham, MA, USA). Surveyor photo diode array (PDA) detector (Thermo Fisher Scientific) was used in LC-UV analysis. It was operated at the wavelengths of $225 \mathrm{~nm}$ and $275 \mathrm{~nm}$, the two absorption maxima of anisomycin (Figure 1A). A reverse-phase Zorbax Eclipse ${ }^{\circledR}$ XDB-C18 column, $75 \mathrm{~mm} \times 4.6 \mathrm{~mm}$ i.d. and $3.5 \mu \mathrm{m}$ particle size (Agilent Technologies, Santa Clara, CA, USA), was used for separation of the compounds. Column temperature was maintained at $35^{\circ} \mathrm{C}$. In front of the separation column, the pre-column was installed: $12.5 \mathrm{~mm} \times 4.6 \mathrm{~mm}$ i.d. and $5 \mu \mathrm{m}$ particle size (Agilent Technologies). The mobile phase consisted of deionized water, methanol and $10 \%$ acetic acid $(79: 20: 1, \mathrm{v} / \mathrm{v} / \mathrm{v})$. The isocratic flow rate of the mobile phase was $0.9 \mathrm{~mL} \mathrm{m^{-1 }}$. An aliquot of $10 \mu \mathrm{L}$ of the solution was injected into the LC system.

\section{Mass spectrometry}

Mass spectra were obtained by LTQ XL (Thermo Fisher Scientific) linear ion trap mass spectrometer. Electrospray was used as the ionization technique in the positive mode. Fragmentation reaction of the most abundant ion in the MS spectrum $(m / z 266$, Figure 1B) to the most intensive fragment ion $(\mathrm{m} / \mathrm{z} 206$, Figure $1 \mathrm{C})$ was used for quantification of anisomycin in the selected reaction monitoring (SRM) mode. The $\mathrm{MS}^{\mathrm{n}}$ study of anisomycin was performed using the following source working parameters: source voltage $(5.0 \mathrm{kV})$, capillary temperature $\left(350{ }^{\circ} \mathrm{C}\right)$ and sheath gas $(47 \mathrm{au}$, i.e. 47 arbitrary units, in the $0-100$ range defined by the LTQ XL system). Helium was used as a collision gas.

\section{Method validation}

The LC-MS/MS method was validated in accordance with $\mathrm{ICH}$ Q2(R1) guideline ( $\mathrm{ICH}$, 

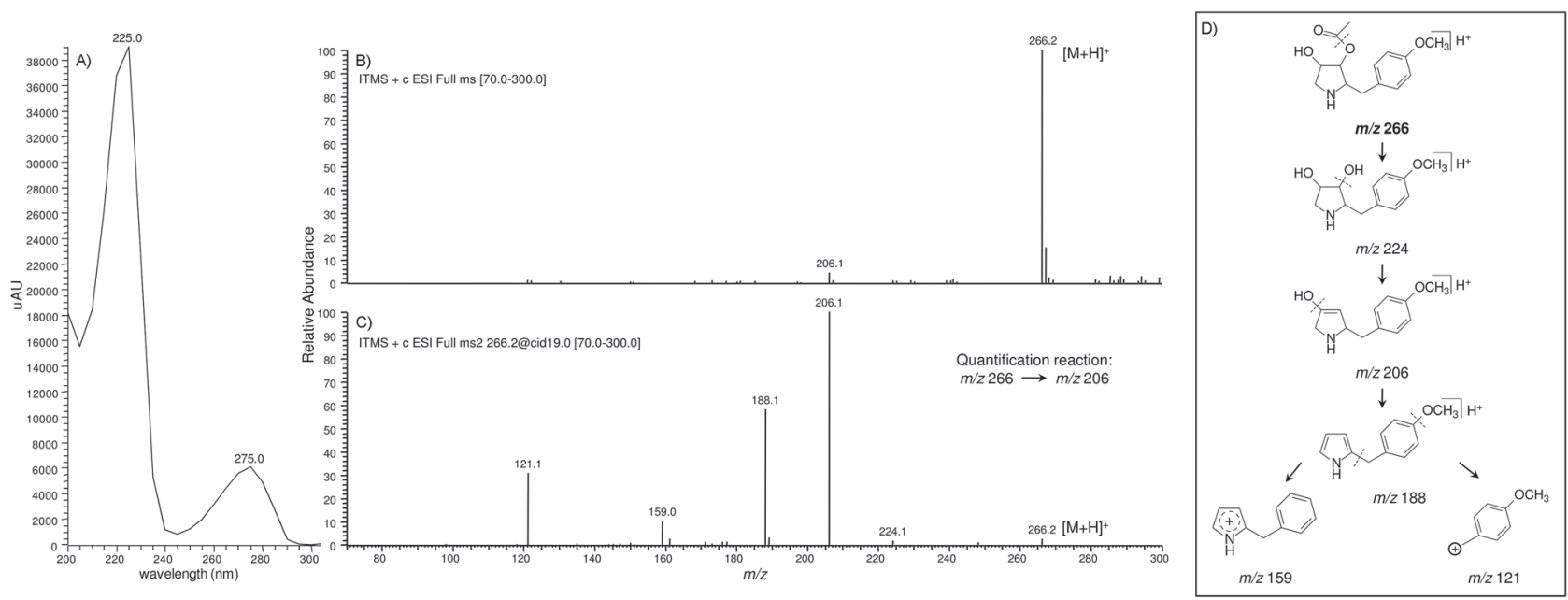

FIGURE 1 - Anisomycin spectra: A) UV spectrum, B) mass spectrum, C) MS/MS spectrum of the protonated molecule, and D) proposed fragmentation pathway of anisomycin.

1994) for the validation of analytical procedures. Investigated validation characteristics of the method were: specificity, accuracy, precision, limit of detection, limit of quantitation, linearity, range, and robustness. The specificity is the ability of an analytical method to reliably assess the analyte in the presence of the matrix components, impurities, degradation products, etc. It was determined by subjecting the drug to stress under various conditions (acidic, alkaline, neutral, oxidative, thermal and photolytic) followed by evaluation of anisomycin separation from the degradation products (Rao et al., 2011; Patel et al., 2015; Runje et al., 2016). Blank and standard solution samples were analyzed simultaneously with the stressed sample.

The accuracy of an analytical procedure expresses the closeness of agreement between the value which is accepted as a true value and the value found. It was determined by analyzing the known concentration of drug in spiked stressed sample (acidic hydrolysis), from the difference between peak areas of fortified and unfortified stressed samples (Ramesh, Rao, Rao, 2014; Patel et al., 2015). The experiment was performed in triplicate at three concentration levels $(700,1000$ and $1300 \mathrm{ng} \mathrm{mL}^{-1}$ ), covering the range $70-130 \%$ of the test concentration ( $\mathrm{ICH}, 1994)$. The accuracy was expressed as the percentage recovery obtained by comparing calculated spiked concentration and true value.

The precision of an analytical procedure expresses the closeness of agreement between a series of measurements obtained from multiple sampling of the same homogeneous sample. It was determined in the same experiments as the accuracy of an analytical procedure. The intra- and interday precision were established by analyzing every spiked stressed sample three times on the same day and on three consecutive days, respectively. The precision was expressed as the relative standard deviation (RSD) of a series of measurements.

Limit of detection (LOD) and limit of quantitation (LOQ) were determined as concentrations of the analyte that would produce a signal to noise ratio of $3: 1$ and 10:1, respectively. These values were determined by injecting the series of anisomycin solutions in the concentration range 1-50 ng mL $\mathrm{mL}^{-1}$ (Luo et al., 2015; Runje et al., 2016).

The linearity of an analytical procedure is its ability (within a given range) to obtain results which are directly proportional to the concentration of analyte in the sample. The range of an analytical procedure is the interval between the upper and lower concentration of analyte in the sample for which it has been demonstrated that the analytical procedure has a suitable level of precision, accuracy and linearity. To establish linearity and range of the method, stock standard solution of anisomycin was diluted to seven concentration levels in the range 700 $1300 \mathrm{ng} \mathrm{mL}^{-1}$. The analysis was carried out in triplicate (Ramesh, Rao, Rao, 2014). The peak areas were plotted against the corresponding concentrations to obtain the calibration graph and the data were subjected to statistical analysis using a linear regression.

The robustness of an analytical procedure is a measure of its capacity to remain unaffected by small, but deliberate variations in method parameters. It provides an indication of the method reliability during normal usage. Variations in the following method parameters were tested: the mobile phase composition (percentage of the organic solvent, $20 \pm 5 \%)$, the flow rate $\left(0.8-1.0 \mathrm{~mL} \mathrm{~min}^{-1}\right)$ and the $\mathrm{pH}$ value $(3.3 \pm 0.1)$, as well as the column temperature 
$\left(35 \pm 5^{\circ} \mathrm{C}\right)$. The experiment was performed in triplicate at three concentration levels (700, 1000 and $\left.1300 \mathrm{ng} \mathrm{mL}^{-1}\right)$.

\section{Forced degradation}

Forced degradation study of anisomycin was performed in accordance with ICH guidelines on stability testing of new drug substances and products (ICH, 2003; ICH, 1996). Experiments were carried out in order to assess the effect of acidic, alkaline and neutral hydrolysis, oxidation, thermal stress, and light on anisomycin stability. ICH guidelines do not define specific stress conditions under which these experiments should be performed, as they depend on the compound characteristics. Stress conditions in this work were selected based on the literature survey (Table I) and adjusted to anisomycin properties.

Generally, the objective of forced degradation is to induce 5-20\% degradation of the active pharmaceutical ingredient (Baertschi, 2005). In this study, some degradation experiments were performed over a longer period of time than suggested and even until complete anisomycin degradation. In the experiment of acidic hydrolysis, $5 \mathrm{~mL}$ of $1 \mathrm{M} \mathrm{HCl}$ was added to $5 \mathrm{~mL}$ of anisomycin stock standard solution in acetonitrile at room temperature. At predetermined time intervals, aliquots of the stressed sample were withdrawn and neutralized with the appropriate volume of $1 \mathrm{M} \mathrm{NaOH}$. Acidic hydrolysis experiment was monitored up to 30 days. All samples were diluted to the expected concentration of $1000 \mathrm{ng} \mathrm{mL}^{-1}$ prior to LC-MS/MS analysis. They were filtered through $0.45 \mu \mathrm{m}$ PVDF (polyvinylidene difluoride) filter acquired from Roth (Karlsruhe, Germany) into the autosampler vials and analyzed.

Alkaline hydrolysis of anisomycin was carried out by mixing $5 \mathrm{~mL}$ of stock standard solution with $5 \mathrm{~mL}$ of $0.1 \mathrm{M} \mathrm{NaOH}$ at room temperature. After $20 \mathrm{~min}$ and $1 \mathrm{~h}$, aliquots of stressed sample were neutralized with the

TABLE I - Literature survey of various stress conditions for degradation of different drugs

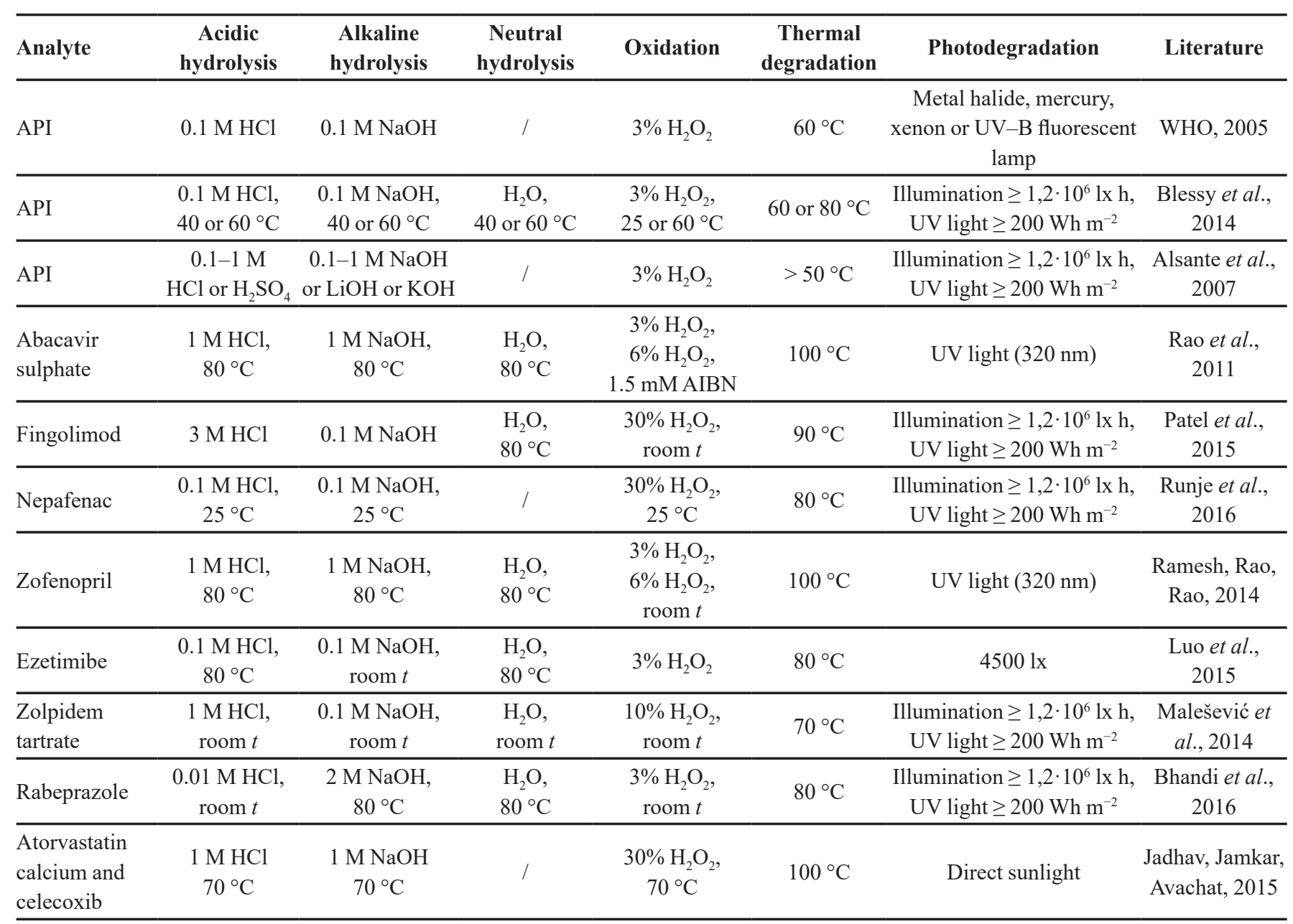

API: active pharmaceutical ingredient, WHO: World Health Organization, UV: ultraviolet, AIBN: 2,2'-azobisisobutyronitrile 
appropriate volume of $0.1 \mathrm{M} \mathrm{HCl}$. Neutral hydrolysis was performed by adding $5 \mathrm{~mL}$ of deionized water to $5 \mathrm{~mL}$ of anisomycin stock standard solution at room temperature. Degradation was monitored for 16 days by analyzing the aliquots withdrawn at predetermined time points.

For oxidative degradation study of anisomycin, $5 \mathrm{~mL}$ of $30 \% \mathrm{H}_{2} \mathrm{O}_{2}$ was added to $5 \mathrm{~mL}$ of stock standard solution at room temperature. Anisomycin oxidation was monitored up to 30 days. The effect of thermal stress on anisomycin stability was estimated in the experiments of acidic and neutral hydrolysis performed at $60{ }^{\circ} \mathrm{C}$ in a water bath for $48 \mathrm{~h}$.

The photolytic degradation study was done by exposing the stock standard solution of the drug to Osram Ultra Vitalux $^{\circledR} 300 \mathrm{~W}$ lamp at a distance of $40 \mathrm{~cm}$ for $6 \mathrm{~h}$ in order to achieve an overall illumination of not less than 1.2 million $\mathrm{lx}$ h and an overall energy of $200 \mathrm{Wh} \mathrm{m}^{-2} \mathrm{UV}$ light (ICH, 1996) in the photostability chamber. Along with the stressed sample, stock standard solution of anisomycin was kept in dark under the same conditions and for the same period of time to serve as a dark control.

In every forced degradation experiment, appropriate blank sample and anisomycin standard solution were simultaneously analyzed with the stressed samples.

\section{RESULTS AND DISCUSSION}

\section{$M^{n}$ study of anisomycin}

The mass analysis of the precursor ion $(\mathrm{m} / z$ 266.2) of the drug produced five fragment ions at $m / z 224.1$, 206.1, 188.1, 159.0 and 121.1 (Figure 1C). The proposed fragmentation pathway of anisomycin is summarized in Figure 1D. It is proposed that the fragment ion $\mathrm{m} / \mathrm{z} 224.1$ is formed by the loss of the acetyl group at the position 3 of the pyrrolidine ring. In subsequent $\mathrm{MS}^{3}$ studies $\mathrm{m} / \mathrm{z}$ 224.1 ion fragmented into four daughter ions $\mathrm{m} / \mathrm{z} 206.1$, 188.1, 159.0 and 121.1. The dominant fragment ion $(\mathrm{m} / \mathrm{z}$ 206.1) is probably formed by the loss of the hydroxyl group at the same position of the pyrrolidine ring. It is proposed that double bond is then formed in the ring. Furthermore, ion $\mathrm{m} / \mathrm{z} 206.1$ is fragmented into three fragment ions $\mathrm{m} / z$ 188.1, 159.0 and 121.1. The product ion $m / z 188.1$ is possibly formed by the loss of another hydroxyl group at the position 4 of the pyrrolidine ring, and formation of another double bond. Finally, ion $\mathrm{m} / \mathrm{z}$ 188.1 is fragmented into ions $\mathrm{m} / \mathrm{z} 159.0$ and 121.1 . It is proposed that daughter ion $\mathrm{m} / \mathrm{z} 159.0$ is formed by the loss of the pyrrolidine ring moiety and the ion $\mathrm{m} / \mathrm{z}$ 121.1 is formed by the loss of the methoxy group of the benzene ring.

\section{Method validation}

Specificity of the method was determined by assessing the anisomycin in the presence of stress reagents and degradation products. It was observed that anisomycin was well separated from its degradation product (Figure 2C), which unambiguously confirms the specificity of the method. Chromatogram of the blank sample (Figure 2A) did not show any interference at the retention time of the drug or its degradation product.

The results obtained for accuracy and precision at the tested concentration levels (Table II) showed that the method is accurate and reliable. The recovery of anisomycin in the presence of stress reagents and degradation product ranged from $98.8 \%$ to $100.5 \%$. RSD values of intra- $(0.3 \%-1.6 \%)$ and interday $(2.8 \%-4.1 \%)$ precision indicate good repeatability of the method.

The LOD and LOQ values were found to be $2.5 \mathrm{ng} \mathrm{mL}^{-1}$ and $8.3 \mathrm{ng} \mathrm{mL}^{-1}$, respectively, indicating that the method for determination of anisomycin is very sensitive.

Good linearity was observed in the tested concentration range $700-1300 \mathrm{ng} \mathrm{mL}^{-1}$. The correlation coefficient $\left(R^{2}\right)$ was determined to be 0.9961 .

Robustness of the method was determined by changing the percentage of organic solvent in the mobile phase, flow rate and $\mathrm{pH}$ value of the mobile phase, as well as the column temperature. Obtained RSD values were in the range $2.1-7.4 \%$ (Table III). It can be concluded that small and insignificant changes in the assay values were observed and that the method was robust.

\section{Degradation behavior of anisomycin}

Stressed samples obtained under various conditions were directly injected into mass spectrometer in order to identify present ions, i.e. degradation products. Degradation of anisomycin, to a different extent, was observed under all tested stress conditions. Only one degradation product was detected in all experiments (Figure S1, Supplementary information session and Figure 2). As it can be seen in Figure $\mathrm{S} 1$ as well as in Figure 2C, the dominant ion in mass spectra of the stressed samples, besides anisomycin ( $\mathrm{m} / \mathrm{z} 266)$, is the ion with $\mathrm{m} / \mathrm{z}$ value 224 . This compound was previously identified as deacetylanisomycin (Reddy, Rao, 2011; Tolić et al., 2015). Mass and MS/MS spectra of deacetylanisomycin are presented in Figure 3. In $\mathrm{MS}^{2}$ analysis, deacetylanisomycin ion is fragmented into four daughter ions with $\mathrm{m} / \mathrm{z}$ values of 206.1, 188.1, 159.0 and 121.1 (Figure 3B). Fragmentation reaction of the precursor ion $(\mathrm{m} / \mathrm{z} 224)$ to the most intensive fragment ion $(\mathrm{m} / \mathrm{z} 188)$ 

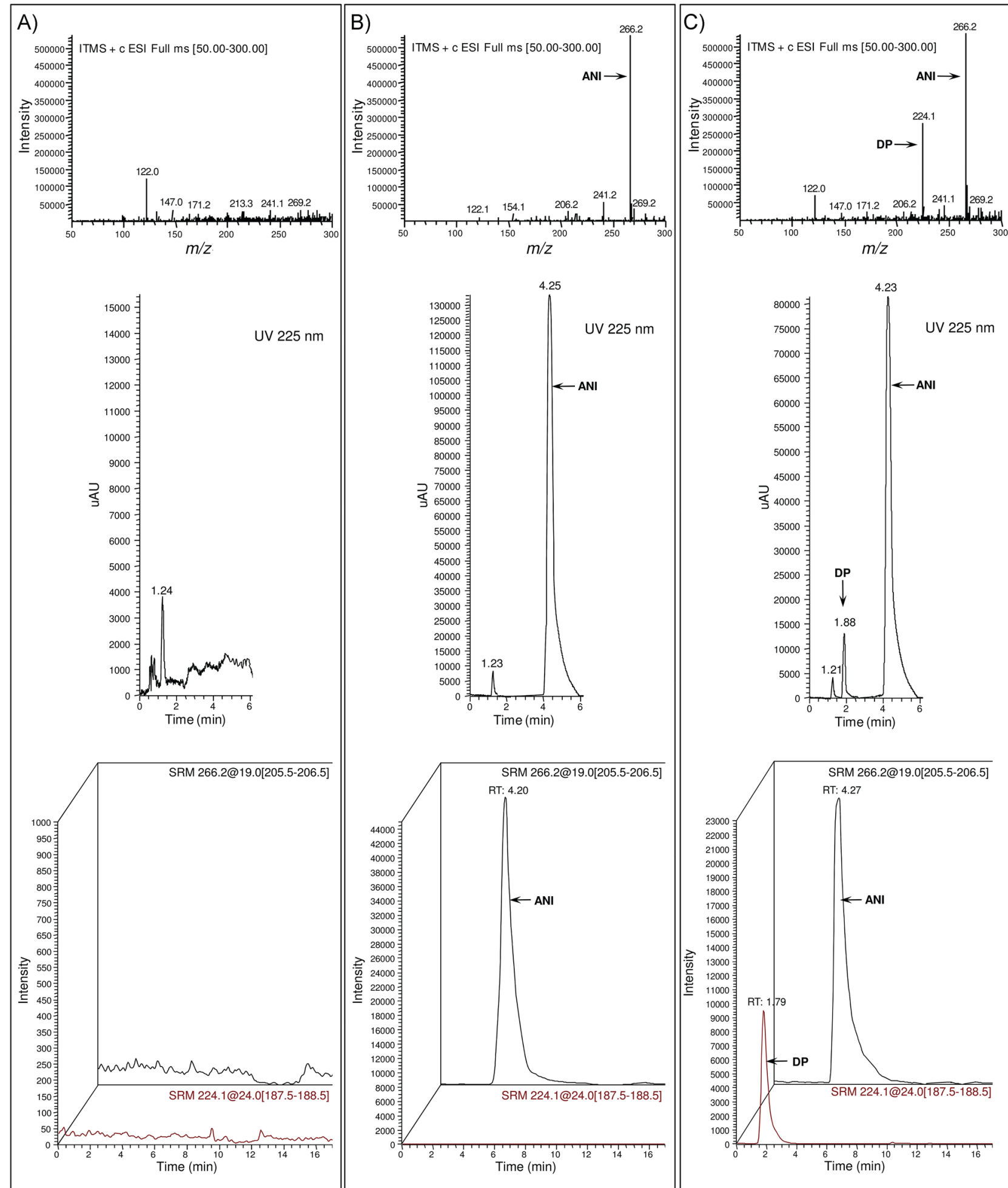

FIGURE 2 - Mass spectra, LC-UV and LC-MS/MS chromatograms of: A) blank sample, B) standard solution of anisomycin (ANI), C) stressed sample (neutral hydrolysis) with degradation product (DP).

was selected for determination of deacetylanisomycin in LC-MS/MS analysis. Proposed fragmentation pathway of deacetylanisomycin and structures of its fragment ions are presented in Figure 3C. This degradation product is most probably formed by deacetylation of anisomycin pyrrolidine ring (Figure 3D). It is interesting to point out that the removal of the acetyl group significantly reduces anisomycin activity (Grollman, 1967). After mass analysis of the stressed 
TABLE II - Accuracy $(n=3)$ and precision $(n=9)$ of the method

\begin{tabular}{|c|c|c|c|c|}
\hline \multirow[b]{2}{*}{$\begin{array}{l}\text { Concentration } \\
\left(\mathbf{n g ~ m L ^ { - 1 } )}\right.\end{array}$} & \multicolumn{2}{|c|}{ Accuracy } & \multirow{2}{*}{$\begin{array}{c}\text { Intraday precision } \\
\text { Measured } \\
\text { concentration } \pm \text { SD } \\
\left(\text { ng mL }^{-1}\right) ; \\
\text { RSD }(\%) \\
\end{array}$} & \multirow{2}{*}{$\begin{array}{c}\text { Interday precision } \\
\text { Measured } \\
\text { concentration } \pm \text { SD } \\
\left(\text { ng mL } \mathbf{~}^{-1}\right) ; \\
\text { RSD }(\%)\end{array}$} \\
\hline & $\begin{array}{c}\text { Calculated spiked } \\
\text { concentration } \pm \text { SD } \\
\left(\mathbf{n g} \mathbf{~ m L}^{-1}\right) ; \\
\text { RSD }(\%)\end{array}$ & Recovery (\%) & & \\
\hline 700 & $691.5 \pm 33.4 ; 4.8$ & 98.8 & $701.4 \pm 1.9 ; 0.3$ & $682.0 \pm 22.4 ; 3.3$ \\
\hline 1000 & $997.4 \pm 13.9 ; 1.4$ & 99.7 & $990.2 \pm 13.9 ; 1.4$ & $1013.3 \pm 41.3 ; 4.1$ \\
\hline 1300 & $1306.3 \pm 64.0 ; 4.9$ & 100.5 & $1315.1 \pm 21.3 ; 1.6$ & $1334.6 \pm 36.9 ; 2.8$ \\
\hline
\end{tabular}

TABLE III - Robustness of the method

\begin{tabular}{|c|c|c|c|c|}
\hline \multirow{2}{*}{$\begin{array}{l}\text { Concentration } \\
\left(\text { (ng mL } \mathbf{~ L ~}^{-1}\right)\end{array}$} & Organic solvent & Flow rate & pH value & Column temperature \\
\hline & \multicolumn{4}{|c|}{ RSD (\%) } \\
\hline 700 & 7.2 & 6.2 & 5.8 & 2.1 \\
\hline 1000 & 7.0 & 5.1 & 5.5 & 2.2 \\
\hline 1300 & 7.4 & 5.6 & 6.4 & 2.4 \\
\hline
\end{tabular}

samples, they were analyzed using the validated method. Typical SRM chromatograms are presented in Figure 4.

Investigation of anisomycin degradation behavior showed that, under alkaline and thermal (neutral) conditions, anisomycin exhibited high instability, while it was moderately stable under acidic, neutral, oxidative, thermal (acidic) and photolytic conditions (Table IV). Moreover, the lowest degradation level was observed in the case of light and oxidation stress. Degradation of the drug under different stress conditions and formation of its degradation product over time are shown in Figure 5. The amount of deacetylanisomycin was determined relative to anisomycin amount under the assumption that it was a single degradation product.

The most rapid degradation was achieved under alkaline conditions. After just one hour, anisomycin was completely degraded (Table IV, Figure 5B). The heat seems to accelerate the drug degradation process. At room
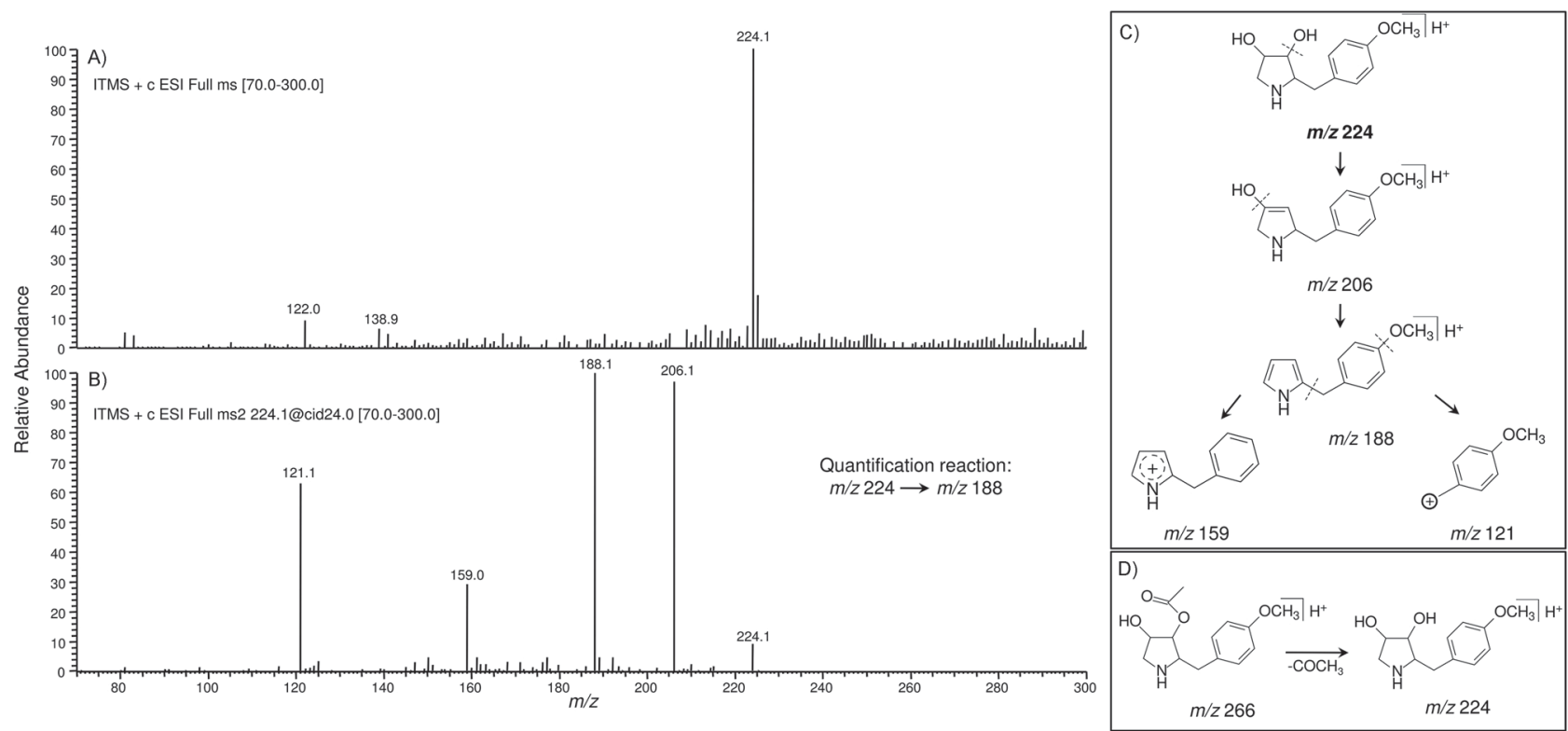

FIGURE 3 - Deacetylanisomycins': A) mass spectrum, B) MS/MS spectrum, C) proposed fragmentation pathway, D) proposed formation by anisomycin degradation. 

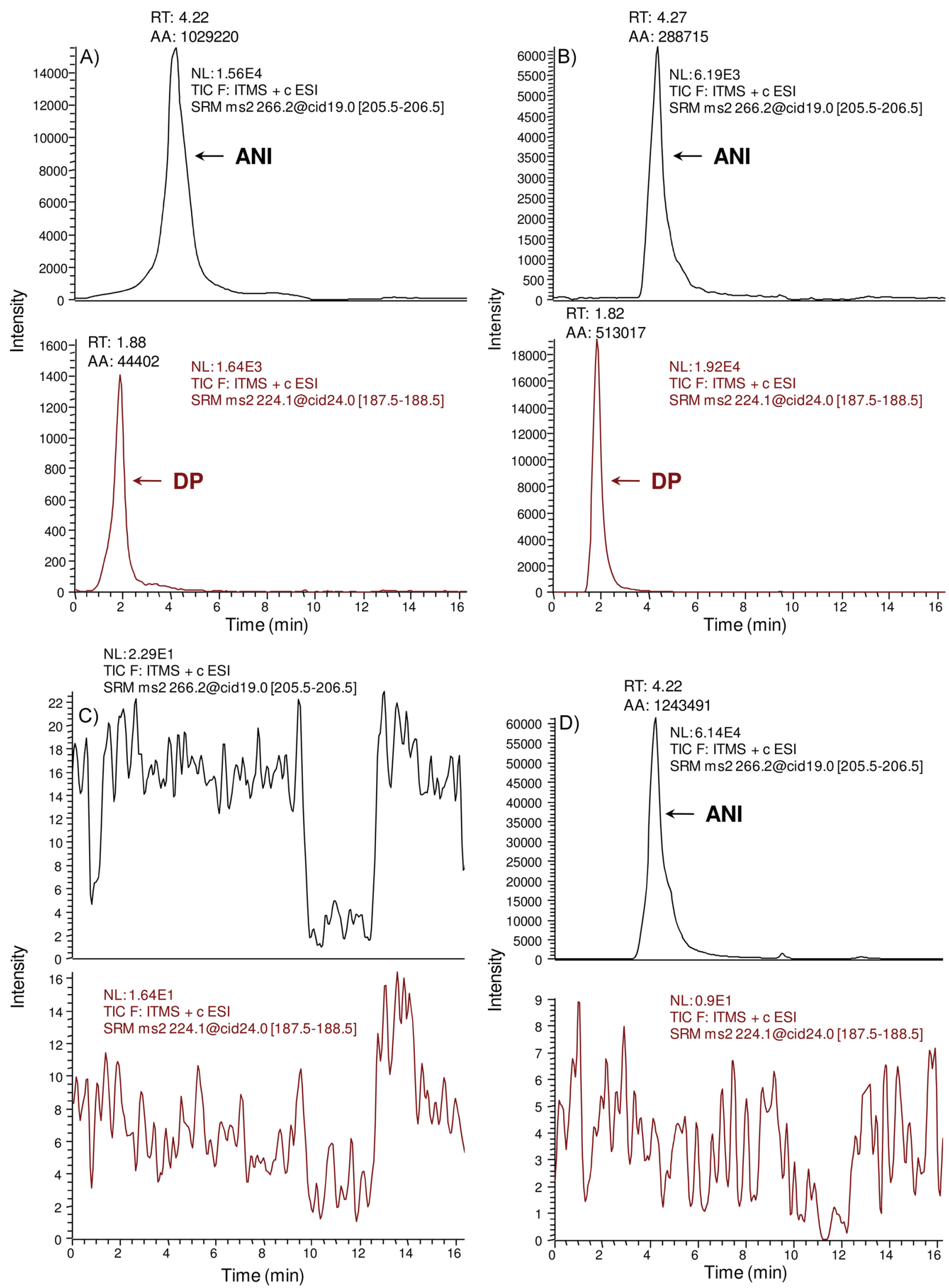

FIGURE 4 - SRM chromatograms of anisomycin (ANI) and its degradation product (DP): A) acidic hydrolysis, B) alkaline hydrolysis, C) blank, D) anisomycin standard solution. 

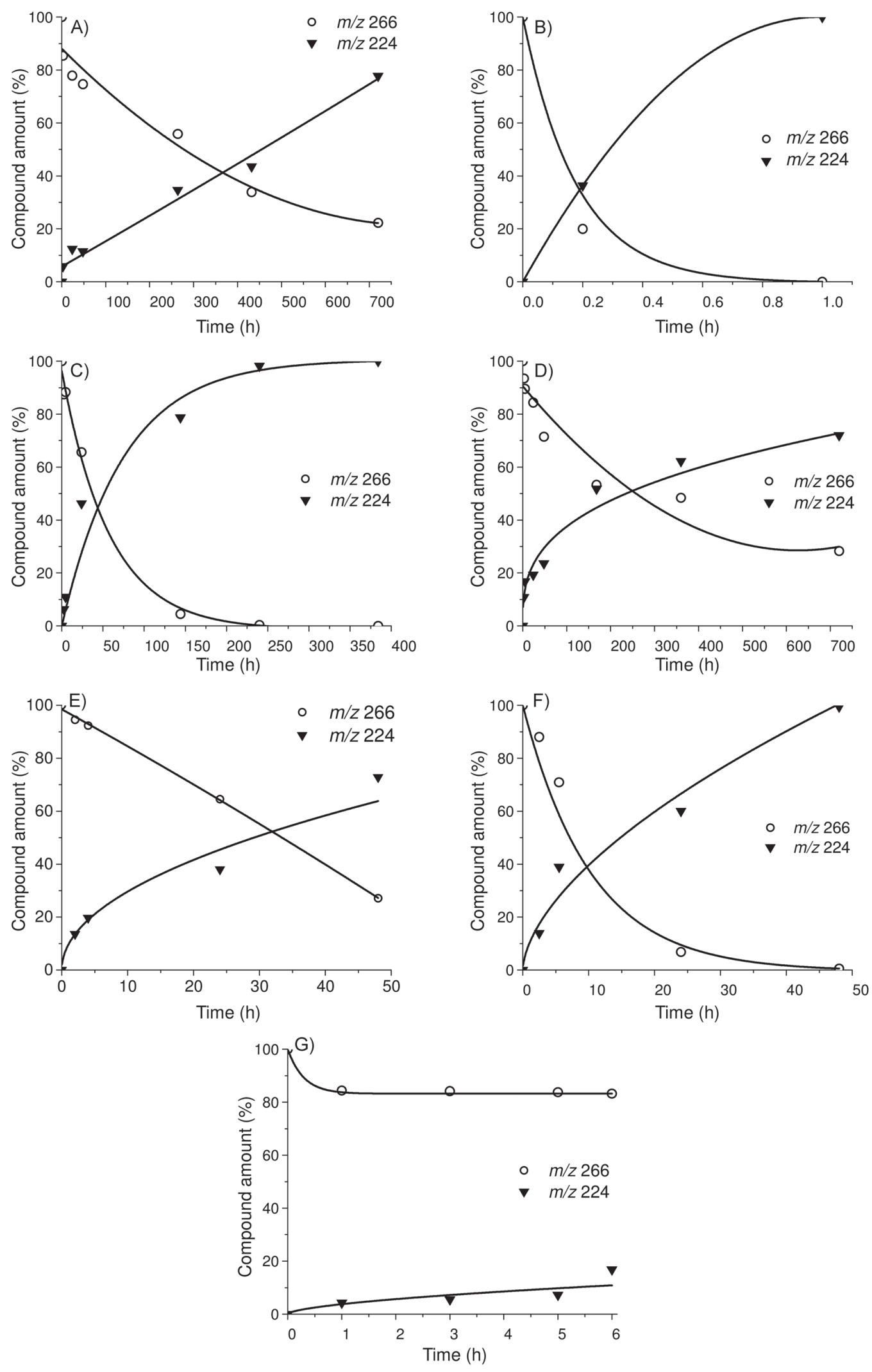

FIGURE 5 - Anisomycin $(\circ)$ degradation and degradation product $(\boldsymbol{\nabla})$ formation under different stress conditions: A) acidic hydrolysis, B) alkaline hydrolysis, C) neutral hydrolysis, D) oxidation, E) thermal degradation (acidic hydrolysis), F) thermal degradation (neutral hydrolysis), G) photolysis. 
TABLE IV - Degradation percent of anisomycin under different stress conditions

\begin{tabular}{|c|c|c|c|c|c|}
\hline \multicolumn{2}{|c|}{ Stress conditions } & $\begin{array}{l}\text { Time } \\
\text { (h) }\end{array}$ & $\begin{array}{c}\text { Expected } \\
\text { concentration } \\
\left(\mathbf{n g ~ m L} \mathbf{~ L}^{-1}\right)\end{array}$ & $\begin{array}{c}\text { Found } \\
\text { concentration } \\
\left(\mathbf{n g ~ m L} \mathbf{~ L}^{-1}\right)\end{array}$ & $\begin{array}{c}\text { Degradation } \\
(\%)\end{array}$ \\
\hline \multicolumn{2}{|l|}{ Acidic } & 24 & 1000 & 778.7 & 22.1 \\
\hline \multicolumn{2}{|l|}{ Alkaline } & 1 & 1000 & 0 & 100.0 \\
\hline \multicolumn{2}{|l|}{ Neutral } & 24 & 1000 & 656.0 & 34.4 \\
\hline \multicolumn{2}{|l|}{ Oxidative } & 24 & 1000 & 843.4 & 15.7 \\
\hline \multirow[t]{2}{*}{ Thermal } & (acidic) & 24 & 1000 & 645.6 & 35.4 \\
\hline & (neutral) & 24 & 1000 & 67.8 & 93.2 \\
\hline \multicolumn{2}{|l|}{ Photolytic } & 6 & 1000 & 832.1 & 16.8 \\
\hline
\end{tabular}

temperature, it takes one month for anisomycin to be degraded by $77.7 \%$ in the presence of acid (Figure $5 \mathrm{~A}$ ). When the temperature is raised to $60{ }^{\circ} \mathrm{C}$, the same degradation level is achieved after $48 \mathrm{~h}$ (Figure 5E). This phenomenon is even more pronounced under neutral conditions. It took 15 days for drug to be completely degraded at room temperature (Figure $5 \mathrm{C}$ ), whereas at $60^{\circ} \mathrm{C}$ anisomycin was completely degraded after $48 \mathrm{~h}$ (Figure $5 \mathrm{~F}$ ).

In the presence of oxidizing reagent, the drug was moderately stable. After 30 days of being exposed to $30 \% \mathrm{H}_{2} \mathrm{O}_{2}$, anisomycin degraded to $28.2 \%$ of the initial amount (Figure 5D). As for the exposure to light source recommended by ICH guideline, anisomycin remained rather stable. After the illumination period of one hour, $15.6 \%$ of the drug degraded and in the next five hours no significant degradation was observed (Figure 5G).

\section{CONCLUSIONS}

Stability of anisomycin was examined by performing forced degradation study that includes investigation of susceptibility of the drug to hydrolysis (acidic, alkaline and neutral), oxidation, light and thermal stress, in accordance with ICH Q1A(R2) and Q1B guidelines. The simple and rapid stability-indicating LC-UV and LC-MS/MS methods were used for investigation of the drug degradation and identification of the degradation product. The optimized LC-MS/MS method was validated according to ICH Q2(R1) guidelines and it was found to be accurate, precise, sensitive, linear and robust. The stability-indicating method also exhibited high specificity, as it was able to separate anisomycin from its degradation product. It was shown that anisomycin was highly unstable under alkaline and thermal (neutral) conditions, while it was moderately stable under acidic, neutral, oxidative, thermal (acidic) and photolytic conditions. The lowest degradation level of anisomycin was observed in the case of light and oxidation stress. The same degradation product was formed under all applied conditions. It was identified as deacetylanisomycin, compound that has significantly reduced activity compared to anisomycin.

\section{ACKNOWLEDGEMENT}

The authors gratefully appreciate the support from the Ministry of Education, Science and Technological Development of the Republic of Serbia (Project No. 172007).

\section{REFERENCES}

Abdel-Aal T, Abdelwahed N, Awad G, El Diwany AI, Haroun B. Improvement of anisomycin production through mutation and medium optimization for Streptomyces griseolus. Aust J Basic Appl Sci. 2011;5(12):2637-2648.

Alsante KM, Ando A, Brown R, Ensing J, Hatajik TD, Kong $\mathrm{W}$ et al. The role of degradant profiling in active pharmaceutical ingredients and drug products. Adv Drug Deliv Rev. 2007;59(1):29-37.

Baertschi SW. Pharmaceutical stress testing: predicting drug degradation. Boca Raton: Taylor \& Francis Group; 2005.

Barbacid M, Vazquez D. $\left[{ }^{3} \mathrm{H}\right]$ anisomycin Binding to Eukaryotic Ribosomes. J Mol Biol. 1974;84(4):603-623.

Bhandi MM, Borkar RM, Shankar G, Raut S, Nagesh N, Srinivas R. Identification and characterization of stressed degradation products of rabeprazole using LC-ESI/MS/MS and ${ }^{1} \mathrm{H}-\mathrm{NMR}$ experiments: in vitro toxicity evaluation of major degradation products. RSC Adv. 2016;6:10719-10735. 
Blessy M, Patel R, Prajapati PN, Agrawal YK. Development of forced degradation and stability indicating studies of drugs-A review. J Pharm Anal. 2014;4(3):159-165.

Cohen H, Kaplan Z, Matar MA, Loewenthal U, Kozlovsky N, Zohar J. Anisomycin, a protein synthesis inhibitor, disrupts traumatic memory consolidation and attenuates posttraumatic stress response in rats. Biol Psychiatry. 2006;60(7):767-776.

Curtin J, Cotter T. Anisomycin activates JNK and sensitises DU 145 prostate carcinoma cells to Fas mediated apoptosis. $\mathrm{Br}$ J Cancer. 2002;87(10):1188-1194.

Food and Drug Administration. FDA. U.S. Department of Health and Human Services, Center for Drug Evaluation and Research (CDER), Center for Veterinary Medicine (CVM), Guidance for Industry: Bioanalytical Method Validation. Rockville; 2001.

Grollman A. Inhibitors of Protein Biosynthesis II. Mode of action of anisomycin. J Biol Chem. 1967;242(13):3226-3233.

Hardt O, Wang S-H, Nader K. Storage or retrieval deficit: The yin and yang of amnesia. Learn Mem. 2009;16(4):224-230.

International Conference of Harmonisation. ICH. Q1A(R2), Stability testing of new drug substances and products. Geneva: International Conference on Harmonization; 2003.

International Conference of Harmonisation. ICH. Q1B, Stability testing: photostability testing of new drug substances and products. Geneva: International Conference on Harmonization; 1996.

International Conference of Harmonisation. ICH. Q2(R1), Validation of analytical procedures: text and methodology. Geneva: International Conference on Harmonization; 1994.

Jadhav P, Jamkar P, Avachat A. Stability indicating method development and validation for simultaneous estimation of atorvastatin calcium and celecoxib in bulk and niosomal formulation by RP-HPLC. Braz J Pharm Sci. 2015;51(3):653661.

Jin C-Y, Park C, Hong SH, Han MH, Jeong J-W, Xu HD, et al. Synergistic induction of TRAIL-mediated apoptosis by anisomycin in human hepatoma cells via the $\mathrm{BH} 3$-only protein Bid and c-Jun/AP-1 signaling pathway. Biomed Pharmacother. 2013;67(4):321-328.
Kirchmeier RL, Upton RP. Simultaneous determination of vancomycin, anisomycin, and trimethoprim lactate by high pressure liquid chromatography. Anal Chem. 1978;50(2):349351.

LeFevre JW, Maier SE, Deng W. Assignment of the ${ }^{13} \mathrm{C}$ NMR spectrum of anisomycin and the ${ }^{1} \mathrm{H}$ and ${ }^{13} \mathrm{C}$ NMR spectra of deacetylanisomycin. Magn Reson Chem. 1993;31(3):318-320.

Lopez J, Gamache K, Schneider R, Nader K. Memory retrieval requires ongoing protein synthesis and NMDA receptor activity-mediated AMPA receptor trafficking. J Neurosci. 2015;35(6):2465-2475.

Luo Z, Deng Z, Liu Y, Wang G, Yang W, Hou C, et al. Development and validation of a novel stability-indicating HPLC method for the quantitative determination of eleven related substances in Ezetimibe drug substance and drug product. Talanta. 2015;139:67-74.

Macías-Silva M, Vázquez-Victorio G, Hernández-Damián J. Anisomycin is a multifunctional drug: More than just a tool to inhibit protein synthesis. Curr Chem Biol. 2010;4(2):124-132.

Malešević M, Živanović L, Protić A, Radišić M, Laušević M, Jović Z, et al. Stress degradation studies on zolpidem tartrate using LC-DAD and LC-MS methods. Acta Chromatogr. 2014;26(1):81-96.

Nader K, Schafe GE, Le Doux JE. Fear memories require protein synthesis in the amygdala for reconsolidation after retrieval. Nature. 2000;406(6797):722-726.

Patel PN, Kalariya PD, Gananadhamu S, Srinivas R. Forced degradation of fingolimod: Effect of co-solvent andcharacterization of degradation products by UHPLCQ-TOF-MS/MS and ${ }^{1} \mathrm{H}$ NMR. J Pharm Biomed Anal. 2015;115:388-394.

Pena RR, Pereira-Caixeta AR, Moraes MFD, Pereira GS. Anisomycin administered in the olfactory bulb and dorsal hippocampus impaired social recognition memory consolidation in different time-points. Brain Res Bull. 2014;109:151-157.

Ramesh T, Rao PN, Rao RN. LC-MS/MS characterization of forced degradation products of Zofenopril. J Pharm Biomed Anal. 2014;88:609-616. 
Rao RN, Vali RM, Ramachandra B, Raju SS. Separation and characterization of forced degradation products of abacavir sulphate by LC-MS/MS. J Pharm Biomed Anal. 2011;54(2):279-285.

Reddy JS, Kumar AR, Rao BV. A new approach to (+)-anisomycin. Tetrahedron Asymmetry. 2005;16(19):31543159 .

Reddy KS, Rao BV. A facile and stereoselective synthesis of the C-2 epimer of (+)-deacetylanisomycin. Tetrahedron Asymmetry. 2011;22(2):190-194.

Runje M, Babić S, Meštrović E, Nekola I, Dujmić-Vučinić Ž, Vojčić N. Forced degradation of nepafenac: Development and validation of stability indicating UHPLC method. J Pharm Biomed Anal. 2016;123:42-52.

Rusanova EP, Alekhova TA, Fedorova GB, Katrukha GS. An antibiotic complex produced by Streptomyces werraensis $1365 \mathrm{~T}$. Appl Biochem Microbiol. 2000;36(5):486-490.

Ryan TJ, Roy DS, Pignatelli M, Arons A, Tonegawa S. Memory. Engram cells retain memory under retrograde amnesia. Science. 2015;348(6238):1007-1013.

Sobin B, Tanner F. Anisomycin, a new anti-protozoan antibiotic. J Am Chem Soc. 1954;76(15):4053-4053.

Sun M, Xing F, Pan S, Di J, Zeng S, Liu J. Low-dose anisomycin is sufficient to alter the bio-behaviors of Jurkat T cells. Cent Eur J Biol. 2013;8(12):1230-1240.
Tolić Lj, Grujić S, Mojović M, Jovanović M, Lubec G, Bačić $\mathrm{G}$, et al. Determination of anisomycin in tissues and serum by LC-MS/MS: application to pharmacokinetic and distribution studies in rats. RSC Adv. 2016;6:92479-92489.

Tolić Lj, Lović J, Petrović S, Mijin D, Grujić S, Laušević M, et al. Investigation of electrochemical behavior of anisomycin on gold electrode followed by HPLC-MS/MS analysis. Electrochem Commun. 2015;58:20-24.

World Health Organization. WHO. Expert Comittee on Specification for Pharmaceutical Preparations, WHO Technical Report Series 929, Annex 5, Guidelines for registration of fixed-dose combination medicinal products, appendix 3 , pharmaceutical development (or preformulation) studies. Geneva: World Health Organization; 2005.

Xing F, Yu Z, Liu J, Di J, Zeng S, Chen D, et al. Anisomycin inhibits the behaviors of $\mathrm{T}$ cells and the allogeneic skin transplantation in mice. J Immunother. 2008;31(9):858-870.

Zhang LH, Zhang JL, Liu YC, Cao ZY, Han JM, Yang J, et al. Isolation and structural speculation of herbicide-active compounds from the metabolites of Pythium aphanidermatum. J Integr Agric. 2013;12(6):1026-1032.

Received for publication on $16^{\text {th }}$ August 2017 Accepted for publication on $27^{\text {th }}$ October 2017 